\title{
Variation in rainy season precipitation and associated water vapor transport over the Chinese Loess Plateau during 1961-2012
}

\author{
Libin Yan $^{1, *}$, Xiaodong Liu ${ }^{1}$, Yan Zhou ${ }^{2}$ \\ ${ }^{1}$ SKLLQG, Institute of Earth Environment, Chinese Academy of Sciences, Xi'an 710075, PR China \\ ${ }^{2}$ Department of Atmospheric and Oceanic Science, University of Maryland, College Park, Maryland 20742, USA
}

\begin{abstract}
The variation in rainy season precipitation and its associated atmospheric water vapor transport during 1961 to 2012 over the Chinese Loess Plateau (LP) are examined by using precipitation data from 53 in situ stations and the National Centers for Environmental Prediction/National Center for Atmospheric Research (NCEP/NCAR) reanalysis data. The results show that the rainy season (June to September, hereafter JJAS) precipitation over the LP exhibits strong interannual variability, and the whole LP becomes wetter or drier synchronously, while no significant long-term linear trend is observed. The climatological water vapor transport from the southern boundary, which originates from both the Indian and the East Asian monsoons, dominates the JJAS precipitation over the LP, although the moisture from the western boundary carried by the Westerlies plays a non-negligible role. Quantitatively, the water vapor from the western boundary is $\sim 73 \%$ of that from the southern boundary. The interannual variability of JJAS precipitation mainly results from the change in water vapor transport from the southern boundary. A positive rainfall anomaly of $100 \mathrm{~mm}$ is associated with a positive water vapor transport of $\sim 166$ (23) $\mathrm{kg} \mathrm{m}^{-1} \mathrm{~s}^{-1}$ from the southern (western) boundary. Both the composite analysis on moisture transport for the wet years and the regression fields of water vapor transport on the precipitation index of the LP feature a cyclone anomaly centered over the northeastern Indian Ocean and an anticyclone anomaly centered over the Pohai region, which strengthen the moisture transport along the southern boundary of the LP, leading to excessive rainfall.
\end{abstract}

KEY WORDS: Precipitation · Water vapor transport · Loess Plateau

\section{INTRODUCTION}

The Chinese Loess Plateau (LP), sitting over the central north part of China, and covering 7 provinces and the middle reach of the Yellow River, belongs to the wet/arid transition area and, hence, is sensitive to climate change (see Fig. 1a). During recent years, it has suffered severe losses of water and soil (Shi \& Shao 2000), a decrease in annual precipitation ( $\mathrm{Li}$ et al. 2003, Ding et al. 2006) and an increase in reference evapotranspiration ( $\mathrm{Li}$ et al. 2012), exerting negative effects on social and economic development. Temperature and its extremes exhibited pro- found changes over the LP, while precipitation and its extremes, overall, did not change significantly (Li et al. 2010b, Fan et al. 2012). The available ground surface water mainly comes from precipitation; therefore, to elucidate the variation of precipitation over the LP and the associated moisture transport is of extreme importance.

Considering the importance of the hydrological cycle over the LP, some studies have been devoted to this issue. The interannual variation of annual total precipitation amount for 1960 to 2000 exhibits an insignificant declining trend over and around the LP (Liu et al. 2005), accompanied with reduced extreme 
rainfall events (Wang \& Zhou 2005). Summer precipitation over the LP is positively correlated with the allIndian monsoon rainfall and shows a clear 2 to $3 \mathrm{yr}$ periodicity, implying a connection with the atmosphere-ocean interaction in the equatorial Pacific (Yatagai \& Yasunari 1995). Due to the limitation of observational data, former studies mainly focused on an earlier period before 2000. The spatio-temporal characteristics of changes in rainy season precipitation during the period from 1961 up to 2012 are still unclear.

The associated water vapor transport for rainy season rainfall over and around the LP is another issue needing to be addressed. The LP is under the mixed influences of monsoons and the Westerlies (Jin et al. 2006), especially the summer monsoon (Wei et al. 2010). The Westerlies, which flow over the more arid region of central Asia, are considered less important in forming rainfall over and around the LP than the summer monsoon flow (He et al. 2005), which includes the Indian and the East Asian monsoons. However, former studies about the contribution of summer monsoon to precipitation over the LP mainly focused on the summer period (June to August) without considering September, during which the summer monsoon can also bring moisture to the LP. Hence, it is necessary to study the impact of the summer monsoon on the moisture budgets over the LP in the rainy season (June to September: JJAS).

This paper aims to answer the following questions: What are the spatial and temporal characteristics of changes in the rainy season precipitation during the period 1961-2012 over the LP? Where does the atmospheric water vapor over and around the LP come from? And what is the optimal general circulation for transporting more moisture into the LP?

\section{DATA AND METHODS}

\subsection{Data}

The present analysis uses 2 data sets:

(1) This study focuses on the LP areas $\left(32.5^{\circ}-\right.$ $42.5^{\circ} \mathrm{N}, 100^{\circ}-115^{\circ} \mathrm{E}$ ) in which 53 stations evenly sit, as shown in Fig. 1a. Monthly precipitation and temperature data sets from 53 observational stations, without missing data, were released by the National Meteorological Information Center and are used to investigate the spatial and temporal characteristics of rainy season precipitation over the LP. The data sets cover the period 1961-2012, have been homogenized, and thus are of good quality. As shown in
Fig.1a, the 53 stations are uniformly distributed and cover most of the LP. The data sets have been widely used in climate change studies of China (Ren et al. 2005).

(2) The NCEP/NCAR reanalysis data set (Kalnay et al. 1996) during the period 1961-2012 with the horizontal resolution of $2.5^{\circ} \times 2.5^{\circ}$ grid is used to measure the water vapor transport over and around the LP. The data set performs well in estimating the global hydrological cycle and water vapor transport (Trenberth \& Guillemot 1995), including the eastern Asian continent (Zhang 2001, Zhou \& Yu 2005, Feng \& Zhou 2012).

\subsection{Methods}

Following Trenberth \& Guillemot (1995), the vertically integrated water vapor flux over and around the LP is calculated by:

$$
\begin{aligned}
& Q_{u}=\frac{1}{g} \int_{P_{\mathrm{s}}}^{P_{\mathrm{t}}} q u \mathrm{~d} p \\
& Q_{V}=\frac{1}{g} \int_{P_{\mathrm{s}}}^{P_{\mathrm{t}}} q v \mathrm{~d} p
\end{aligned}
$$

where $q, u, v, p$, and $g$ represent specific humidity, zonal wind, meridional wind, pressure and gravitational acceleration, respectively. $P_{\mathrm{s}}$ is surface pressure, and $P_{\mathrm{t}}$ is given the value of $300 \mathrm{hPa}$ in the calculation process as there is little water vapor above $300 \mathrm{hPa}$ (Zhou 2003, Xu et al. 2008). Total water vapor transport can be separated into the stationary component and the transient component, where the stationary component dominantes and the transient component plays a negligible role over East Asia (Zhou \& Yu 2005).

\section{RESULTS AND ANALYSIS}

\subsection{Variation of rainy season precipitation}

The annual cycles of monthly temperature (Fig. 1c) and monthly precipitation (Fig. 1d) averaged over the 53 stations both exhibit peaks in July. The contrasting temperature and precipitation differences between summer and winter indicate the summerwinter monsoons transition. The precipitation during JJAS accounts for $>70 \%$ of the annual total rainfall, implying an obvious monsoon-type precipitation over the LP. The climate mean $850 \mathrm{hPa}$ wind field (JJAS, Fig. 1b) shows that the prevailing summer monsoon exerts profound impact over the LP in JJAS. 

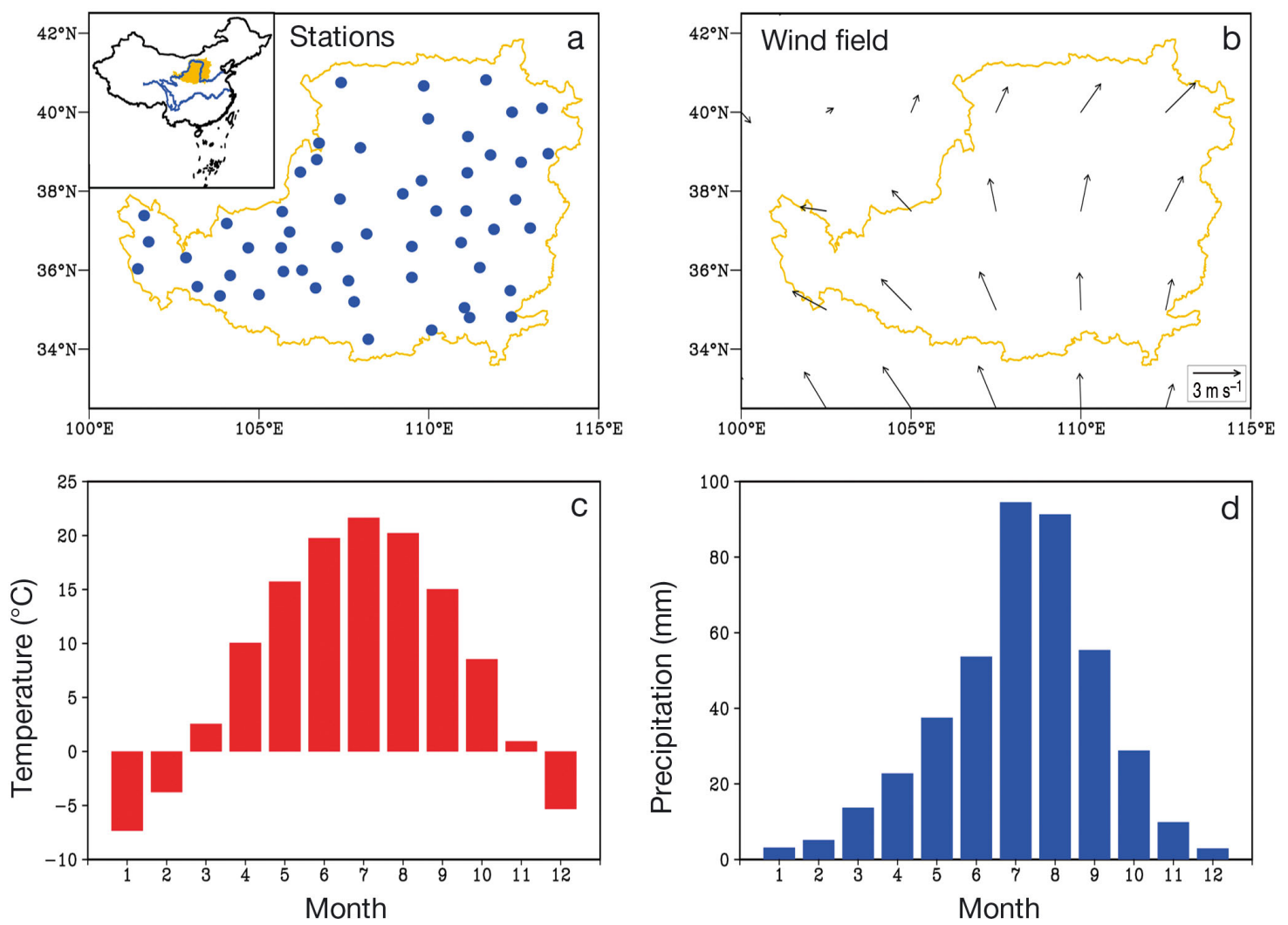

Fig. 1. (a) Location of the 53 observational stations over the Loess Plateau (LP; border shown in a,b), (b) climate mean $850 \mathrm{hPa}$ wind field (zonal and meridional) for June to September, and annual cycles of monthly mean (c) temperature and (d) precipitation averaged for the 53 stations during the period 1961-2012

The monthly $850 \mathrm{~h}$ Pa wind fields show that the summer monsoon over the LP starts in June, prevails through July and August, and ends in September (not shown). The annual cycles of temperature, precipitation and $850 \mathrm{hPa}$ wind fields all demonstrate that it is reasonable to focus on the rainy season (JJAS) precipitation over the LP in the present study.

The spatial distribution of JJAS precipitation over the LP shows a southeast-northwest gradient (Fig. 2a), increasing from $<150 \mathrm{~mm}$ in the northwest to $>400 \mathrm{~mm}$ in the southeast, indicative of the summer monsoon influence. The spatial distribution of JJAS precipitation standard deviation (SD) also exhibits a southeast-northwest gradient (Fig. 2b), suggesting the precipitation is vulnerable to the changes in the extent and intensity of the summer monsoon, especially the stations over the southeastern LP with more rainfall. However, the temporal characteristics of JJAS precipitation at 53 stations for the period 1961-2012 are complicated and do not explicitly exhibit linear trends. As shown in Fig. 2c, the JJAS precipitation of 53 stations generally show decreasing trends, out of which only 8 stations show increasing trends, but just 5 stations are statistically significant at the 0.05 level based on the $t$-test.

The JJAS precipitation over the LP exhibits larger spatial variations (Fig. 2a) and does not show significant linear trends (Fig. 2c); hence we performed the Rotated Empirical Orthogonal Function (REOF) analysis on the JJAS precipitation of 53 stations to detect whether the regional uniform change in precipitation exists or not. Fig. 3 shows the first 2 leading modes and corresponding principal components (PCs). The first PC exhibits strong interannual variability, with the center of the first mode located over northwestern LP (Fig. 3a,c). The second PC also shows strong interannual variability, but the center of the corresponding mode sits over the southeastern LP (Fig. 3b,d). Both the first and second modes (Fig. 3a,b) show a synchronous spatial-pattern, implying that the whole LP would experience a wet or dry year together.

The JJAS precipitation series over the 53 stations have a synchronous spatial pattern as time changes; therefore, we extracted a precipitation index by averaging the JJAS precipitation series over the 53 stations, as shown in Fig. 4a. The mean, SD, and slope 
a) Precipitation (mm), JJAS

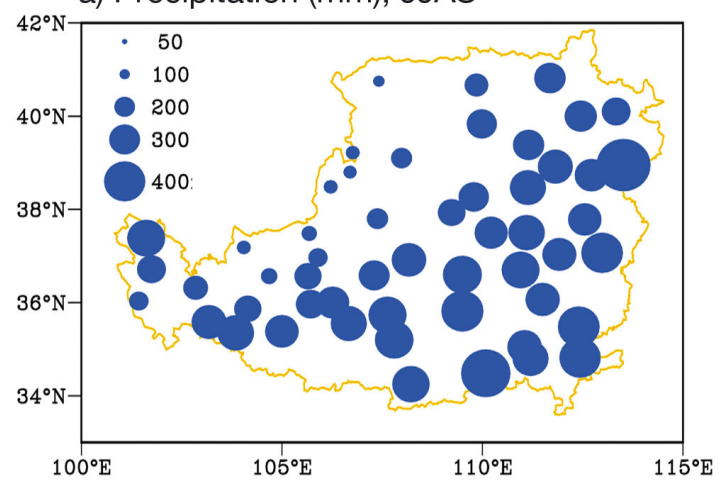

b) SD (mm)

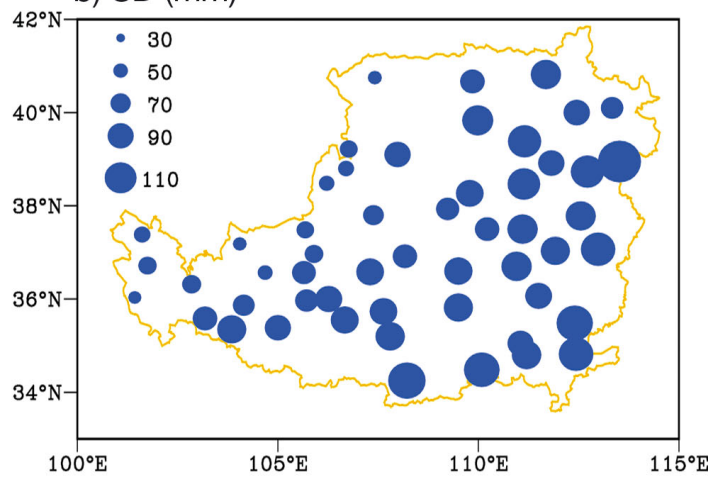

c) Linear trend (mm decade $\left.{ }^{-1}\right)$

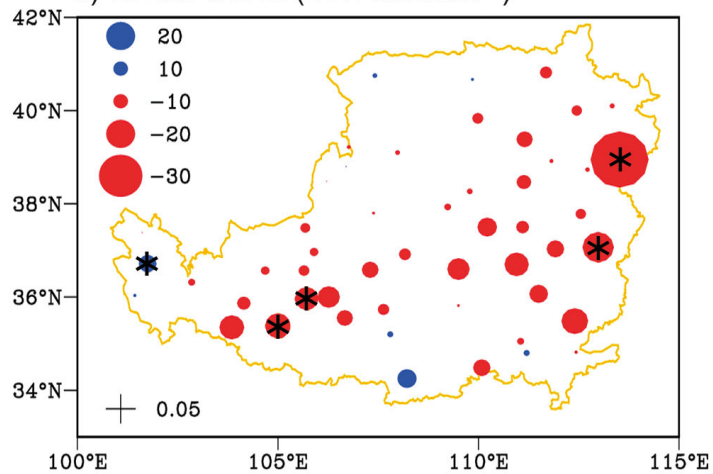

Fig. 2. (a) Climate mean precipitation (Jun-Sep: JJAS) averaged for the period 1961-2012, (b) SD of precipitation and (c) linear trends. (*): $t$-test statistical significance at 0.05 level. Yellow contour: Loess Plateau area
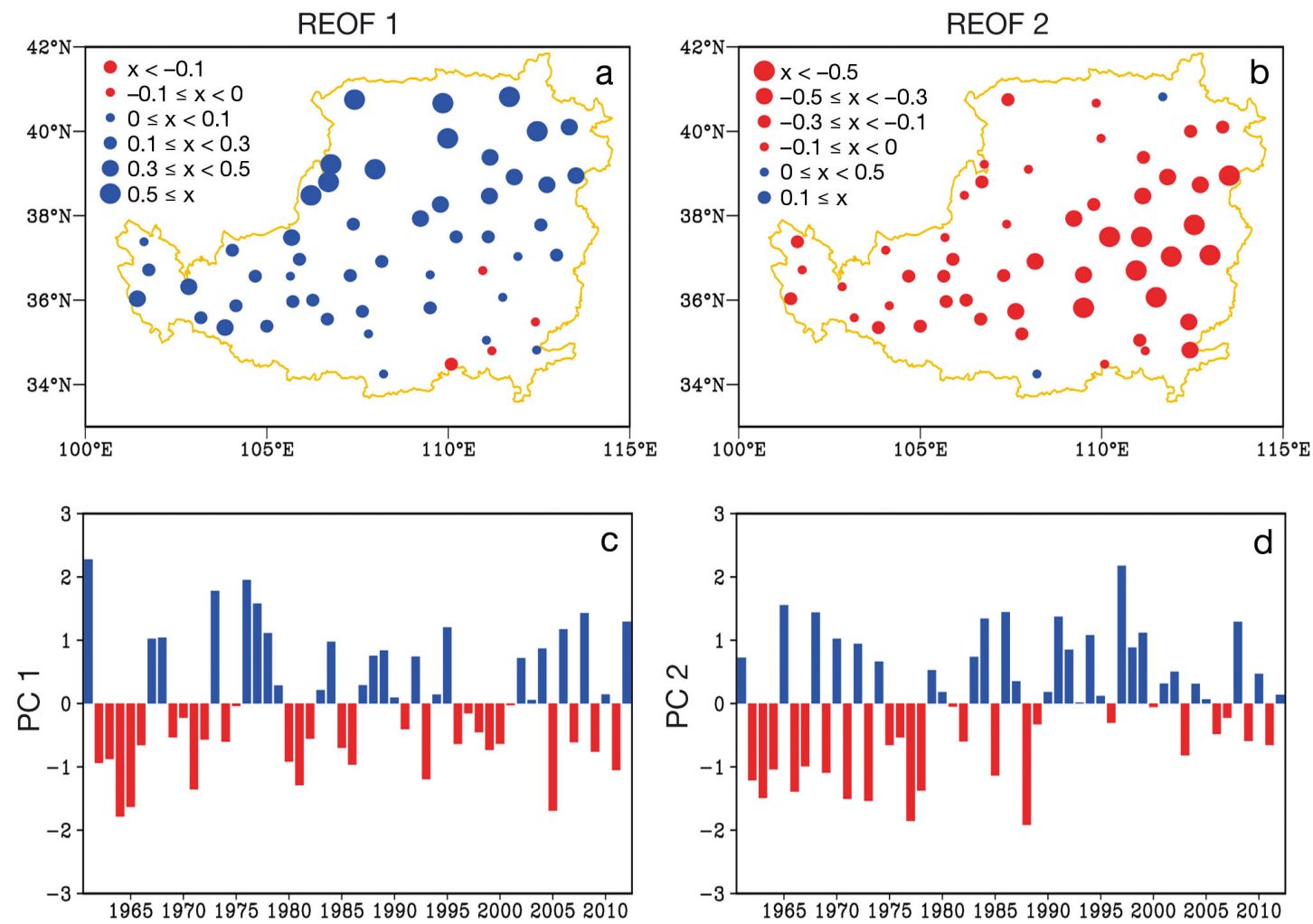

Fig. 3. (a,b) First 2 Rotated Empirical Orthogonal Functions (REOF) leading modes and (c,d) corresponding time series for the rainy season precipitation (Jun-Sep: JJAS) over the Loess Plateau (LP; solid yellow line in a,b) based on 53 stations data. 

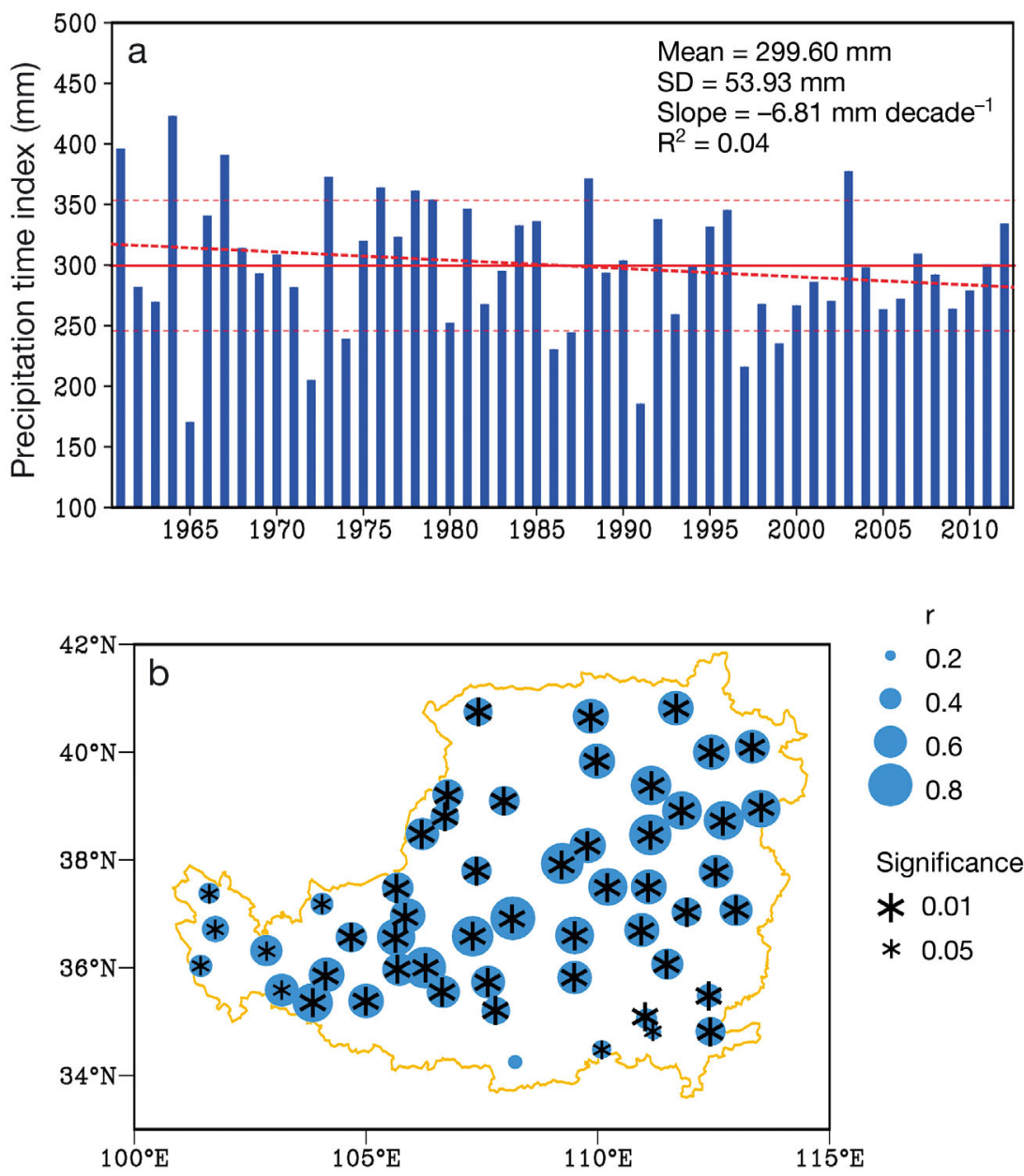

Fig. 4. (a) Rainy season (Jun-Sep) precipitation time index averaged over 53 stations in Loess Plateau (LP; solid yellow line in b). Horizontal lines - solid: mean; thick-dotted: linear fitting; thin-dotted: SDs of the precipitation index. (b) Correlation coefficients ( $\mathrm{r}$ ) between the precipitation time index of the LP and those of each station. (*) Statistical significance of $r$ at 0.01 and 0.05 levels

(linear trend) for the JJAS precipitation index of LP are $299.60,53.93$, and $-6.81 \mathrm{~mm}$ decade $^{-1}$, respectively, but the linear trend is not statistically significant at the 0.05 level, implying an insignificant decreasing trend of JJAS precipitation. The precipitation index of LP is positively correlated with those of 53 stations (Fig. 4b), out of which 50 stations pass the statistical test at the significance level of 0.01 , implying the robust representation of the JJAS precipitation index over the LP. The power spectrum analysis on the precipitation index shows that the rainy season precipitation during 1961-2012 exhibits 2 and 3 yr spectral peaks (figure omitted). Yatagai \& Yasunari (1995) have also reported that the summer precipitation during 1951-1990 features a 2 to 3 yr periodic oscillation, and seems to be closely related to the atmosphereocean interaction in the equatorial Pacific, implying the possible teleconnections with ENSO.

The internannual variability of JJAS rainfall over LP has an SD of $53.93 \mathrm{~mm}$ (18\% of mean). Based on the threshold of $1 \mathrm{SD}$, we classified the index into wet, dry and normal years (Fig. 4a). The wet years include 1961, 1964, 1967, 1973, 1976, 1978, 1979, 1988 and 2003, and the dry years include 1965, 1972, 1974, 1986, 1987 , 1991, 1997 and 1999. We further performed the composite analysis of water vapor transport between the wet and the dry years.

\subsection{Water vapor transport}

The climatological water vapor transport over and around the LP derived from NCEP/NCAR reanalysis is shown in Fig. 5. A box covering $32.5^{\circ}-42.5^{\circ} \mathrm{N}, 100^{\circ}-115^{\circ} \mathrm{E}$ (Fig. 5a) is used to analyze the water vapor transport budget across the 4 boundaries (eastern, southern, western and northern boundaries) of the LP. There are 2 main water vapor channels for the climatological JJAS rainfall over the LP. The first important channel is dominated by the Asian summer monsoon, including the Indian and East Asian Monsoons as shown in Fig. 5a,b. The strong southwesterly water vapor flow associated with the Somali crossequatorial jet carries abundant moisture from the Arabian Sea and the Bay of Bengal into southern China, and finally flows into the LP, mainly through the bottom layer (surface $700 \mathrm{hPa}$, Fig. 5b) of the southern boundary. This channel also merges the water vapor brought by the East Asian monsoon flow of the southwestern edge of Western Pacific Subtropical High.

The second channel is occupied by the midlatitude Westerlies. The Westerlies branch into 2 after encountering the great terrain of the Tibetan Plateau. The northern branch of the Westerlies carries non-negligible water vapor and penetrates into LP mainly through the middle layer (700 to $300 \mathrm{hPa}$ ) of the western and northern boundaries. Hence it is concluded that the Asian summer monsoon and the Westerlies both provide water vapor 

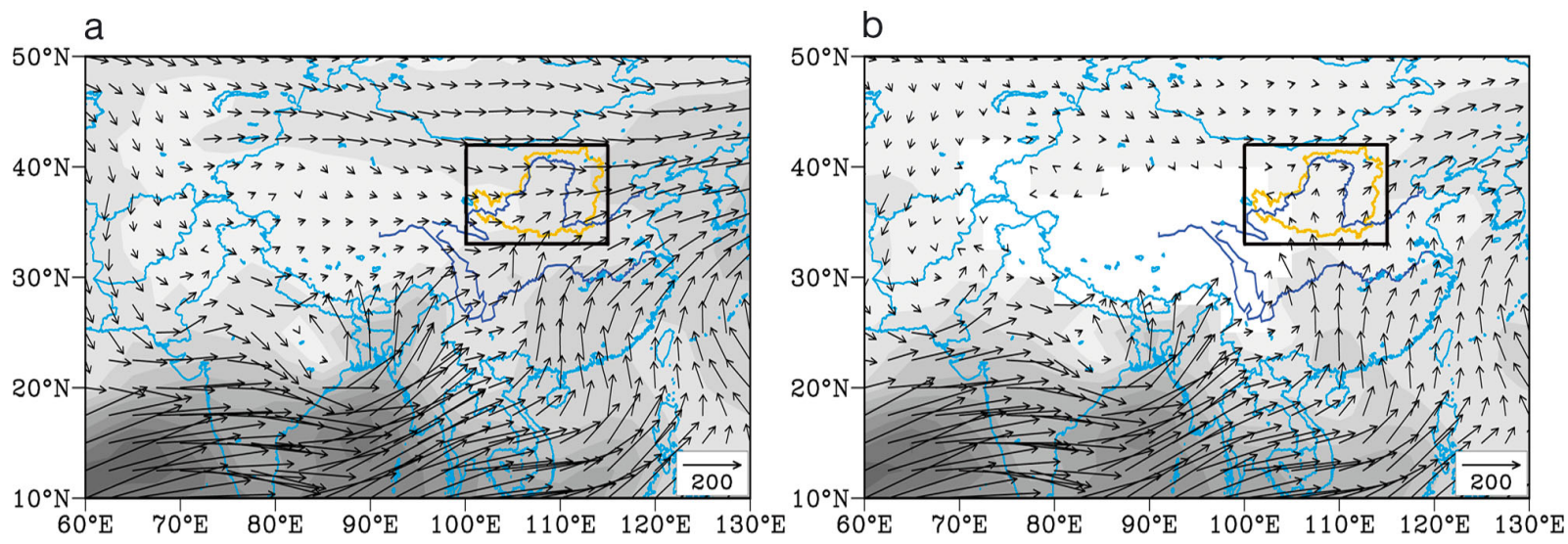

Water vapor transport $\left(\mathrm{kg} \mathrm{m}^{-1} \mathrm{~s}^{-1}\right)$

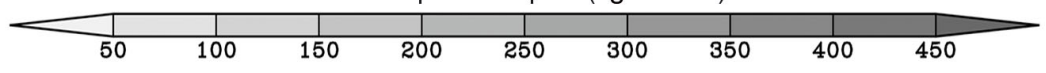

Fig. 5. Rainy season (Jun-Sep) water vapor transport $\left(\mathrm{kg} \mathrm{m}^{-1} \mathrm{~s}^{-1}\right)$ averaged for the period 1961-2012 at 2 layers of the atmospheric column: (a) surface $300 \mathrm{hPa}$ and (b) surface $700 \mathrm{hPa}$. Shading: absolute value of water vapor transport at each grid. Black box $\left(32.5^{\circ}-42.5^{\circ} \mathrm{N}, 100^{\circ}-115^{\circ} \mathrm{E}\right)$ is used to quantitatively measure the water vapor transport across the 4 boundaries (eastern, southern, western and northern boundaries) of the LP (as in Figs. 6-10)

for JJAS precipitation over LP, especially the Asian summer monsoon.

The quantitative estimate of JJAS water vapor transport across the 4 boundaries of LP for the period 1961-2012 is illustrated in Fig. 6. The coverage of the box used to measure water vapor transport is shown in Fig. 6b. In order to explore the vertical distribution of moisture transport, the atmospheric column is divided into the bottom (surface to $700 \mathrm{hPa}$ ), middle (700 to $400 \mathrm{hPa}$ ), and top (400 to $300 \mathrm{hPa}$ ) layers. As shown in Fig. 6a, the southern and western boundaries are the main water vapor incoming channels, and the eastern boundary is the main water vapor outgoing channel. The total water vapor transport from the western boundary accounts for $\sim 73 \%$ of that from the southern boundary in the NCEP/NCAR reanalysis, implying the non-negligible contribution of the Westerly to local rainfall. The Westerlies mainly import water vapor into the LP through both the western and northern boundaries, especially the middle layer of the western boundary. The water vapor input from the southern boundary is concentrated at the bottom layer and decreases gradually from the bottom to top layer, implying that the moisture carried by summer monsoon prevails at the bottom layer. After reaching the LP, the moisture is uplifted by the local atmosphere convection, and exported through the middle layer of the eastern boundary by the prevailing Westerlies and through the bottom layers of the eastern and northern boundaries by summer monsoon.

\subsection{Water vapor transport for wet and dry years}

The water vapor transport and anomalies for wet and dry years are shown in Fig. 7. The composite
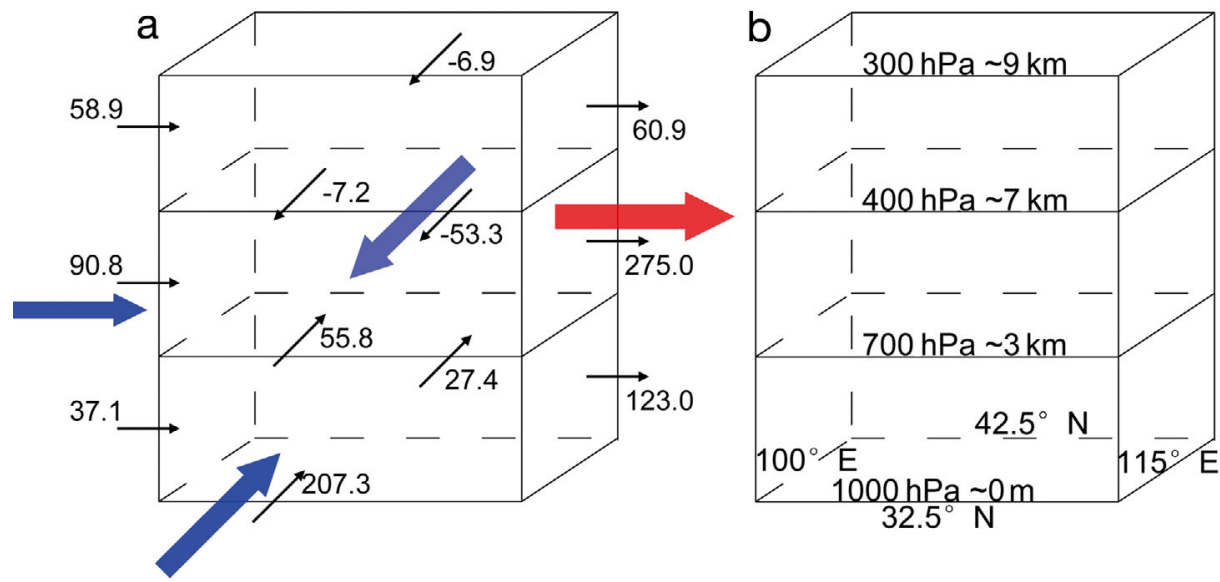

Fig. 6. Vertical distribution of the rainy season (Jun-Sep) water vapor transport (in $\mathrm{kg} \mathrm{m}^{-1} \mathrm{~s}^{-1}$ ) averaged for the period 1961-2012 at the 3 layers (surface to 700 , 700-400, and 400-300 hPa) across the 4 boundaries of the Loess Plateau (see Fig. 5) based on (a) NCEP/NCAR reanalysis and (b) the reference sketch map. Black arrows: transporting directions, blue (red) arrows: main incoming (outgoing) channels. Sizes of color arrows depend on values of the nearest black arrows 
a) Wet years

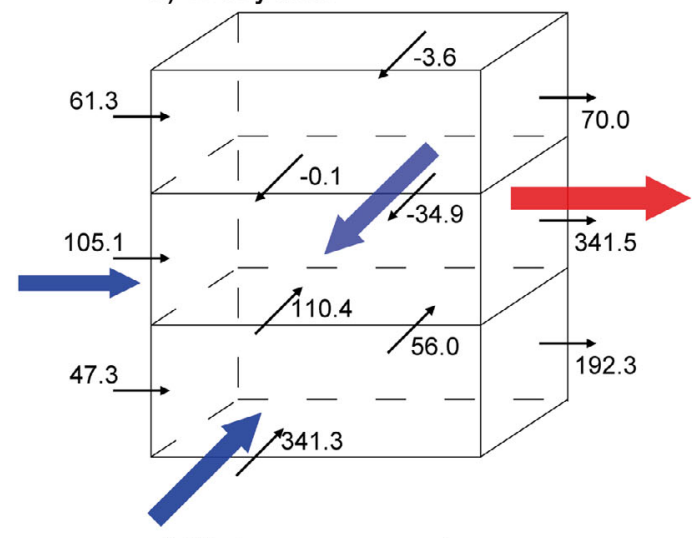

c) Wet years anomaly

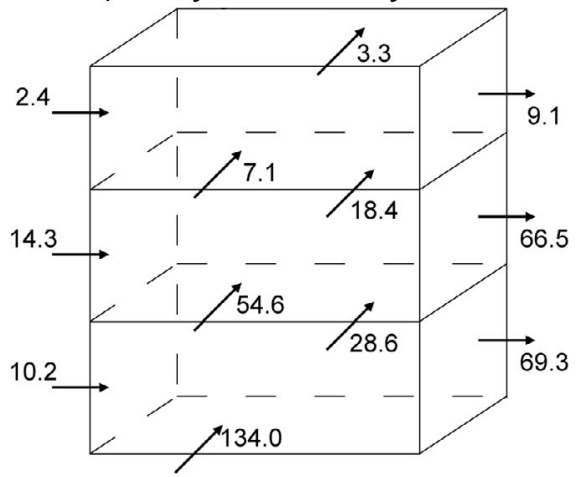

b) Dry years

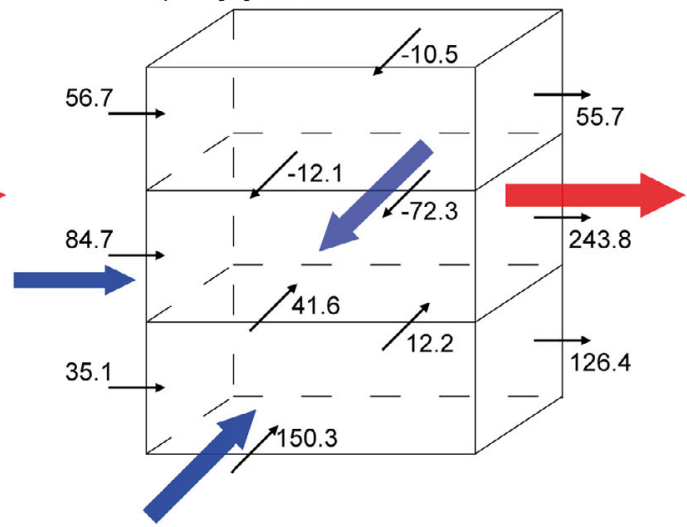

d) Dry years anomaly

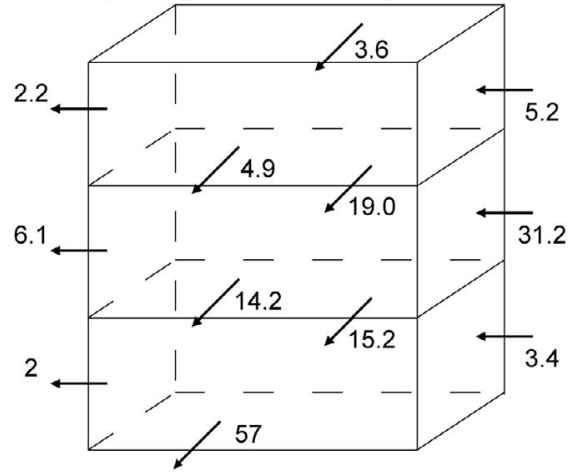

Fig. 7. Vertical distribution of the rainy season (Jun-Sep) water vapor transport (in $\mathrm{kg} \mathrm{m}^{-1} \mathrm{~s}^{-1}$ ) at the 3 layers (surface-700, 700-400, and 400-300 hPa) across the 4 boundaries of the Loess Plateau for (a) wet years, (b) dry years, (c) wet years anomaly, and (d) dry years anomaly. Anomalies are calculated based on the difference between water vapor transport in wet/dry years and the climate mean water vapor transport (see Fig. 6a). See Fig. 6 for explanation of arrows

analysis using NCEP/NCAR reanalysis was performed on the wet/dry years selected according to the JJAS precipitation index (Fig. 4a) of the LP. The water vapor transport structure across the 4 boundaries basically stays consistent with the climate mean transport (Fig. 6a) in wet (dry) years, while the water vapor import from the western and southern boundaries increases (decreases), mostly through the bottom and middle layers of the southern boundary. At the same time, the water vapor export from the northern and eastern boundaries increases (decreases). The quantitative relationship of the difference in water vapor transport from the 4 boundaries versus the change in precipitation between wet and dry years shows that a positive rainfall anomaly of $100 \mathrm{~mm}$ is associated with a positive water vapor import of $\sim 166$ (23) $\mathrm{kg} \mathrm{m}^{-1} \mathrm{~s}^{-1}$ from the southern (western) boundary. Compared with the climate mean transport, the relative change in water vapor transport from the southern boundary is larger than that from the western boundary (Fig. 7c,d), especially in wet years, demonstrating that the moisture carried by the summer monsoon are the crucial factor upon which the variation of JJAS rainfall depends.

To detect the large scale change in moisture transport pattern for the wet and dry years, the JJAS water vapor transport anomalies in the whole column and at the bottom layer were studied (Fig. 8). The large scale pattern of moisture transport (figure omitted) basically keeps consistent with climate mean transport (Fig. 6). However, in the wet years, the anomalies fields (Fig. 8a,c) feature a cyclone anomaly centered at the northeastern Indian Ocean $\left(\sim 21^{\circ} \mathrm{N}\right.$, $\left.66^{\circ} \mathrm{E}\right)$, an anticyclone anomaly centered at the Pohai region $\left(\sim 33^{\circ} \mathrm{N}, 124^{\circ} \mathrm{E}\right)$, and a slight increase in moisture transport by the Westerlies. The features imply the strengthening of Indian and East Asian monsoons and the slight increase in the Westerlies, supporting the quantitative measure of changes in water vapor transport in wet years as illustrated in Fig. 7a,c. In dry years, the reversed anomaly patterns are observed (Fig. 8b,d), while not as obvious as those in wet years.

The regression fields of vertically integrated water vapor transport on the precipitation index are de- 

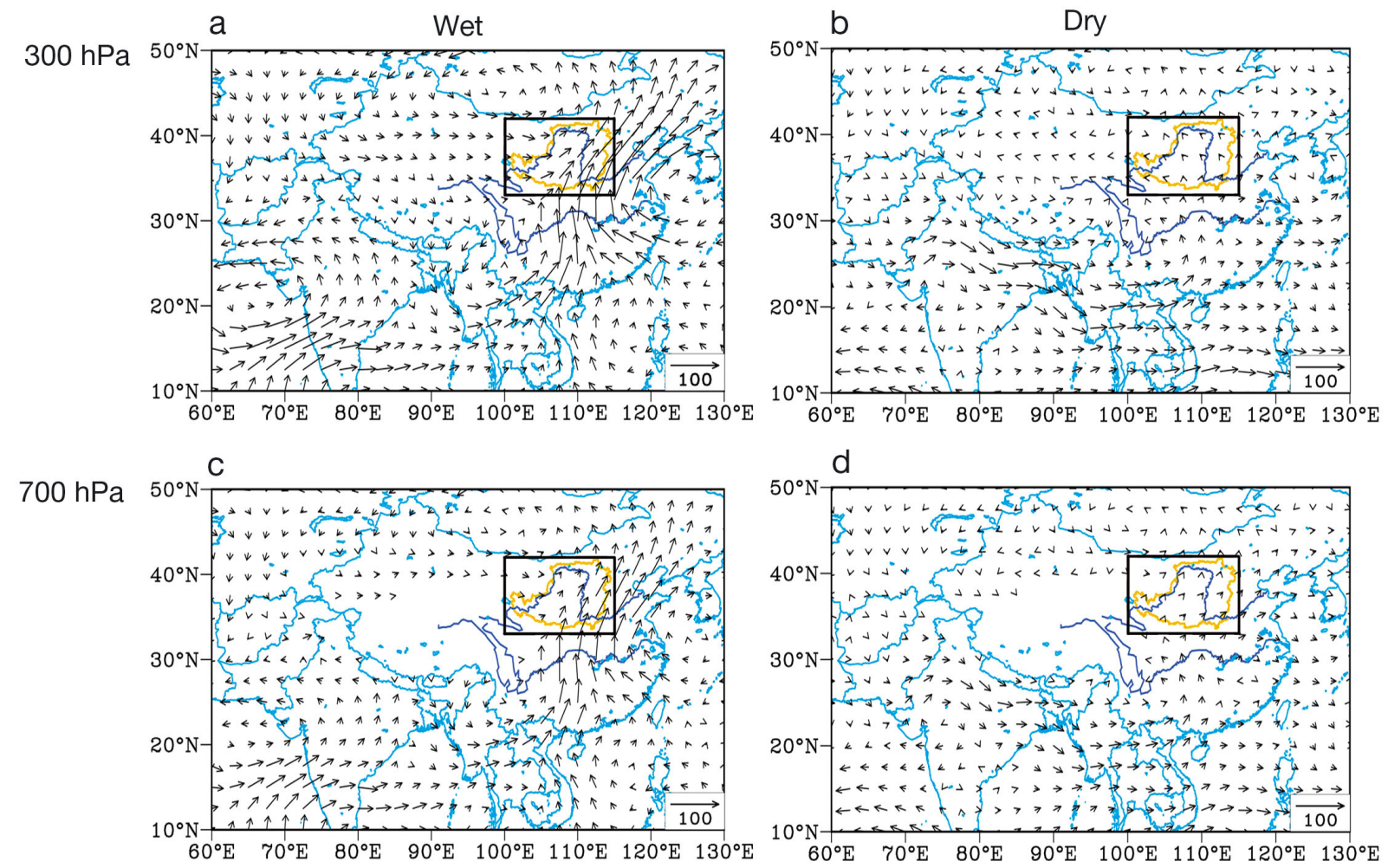

Fig. 8. Rainy season (Jun-Sep) water vapor transport anomalies $\left(\mathrm{kg} \mathrm{m}^{-1} \mathrm{~s}^{-1}\right)$ at the 2 layers of the atmospheric column $(\mathrm{a}, \mathrm{b}$ : surface $300 \mathrm{hPa} ; \mathrm{c}, \mathrm{d}$ : surface $700 \mathrm{hPa}$ ) for $(\mathrm{a}, \mathrm{c})$ wet and $(\mathrm{b}, \mathrm{d})$ dry years. Anomalies are calculated based on the difference between water vapor transport in wet/dry years and the climate mean water vapor transport (see Fig. 5)

picted in Fig. 9. The regression patterns of both the whole column (Fig. 9a) and bottom layer (Fig. 9b) reproduce the cyclone anomaly centered at the northeastern Indian Ocean, the anticyclone anomaly centered at the Pohai region, and the slight increase in moisture transport by the Westerlies. The anomaly and the regression fields both support the argument that the increase in precipitation over the LP is associated with the strengthened Asian summer monsoon and the intensified Westerlies, where the Asian summer monsoon dominates.

To further investigate how the Asian summer monsoon affects the precipitation anomalies, Fig. 10 shows the latitude-pressure cross section of the meridional water vapor transport and wind fields averaged between the western and eastern boundaries of the LP for the wet and dry years. The water vapor transport by the Asian summer monsoon in
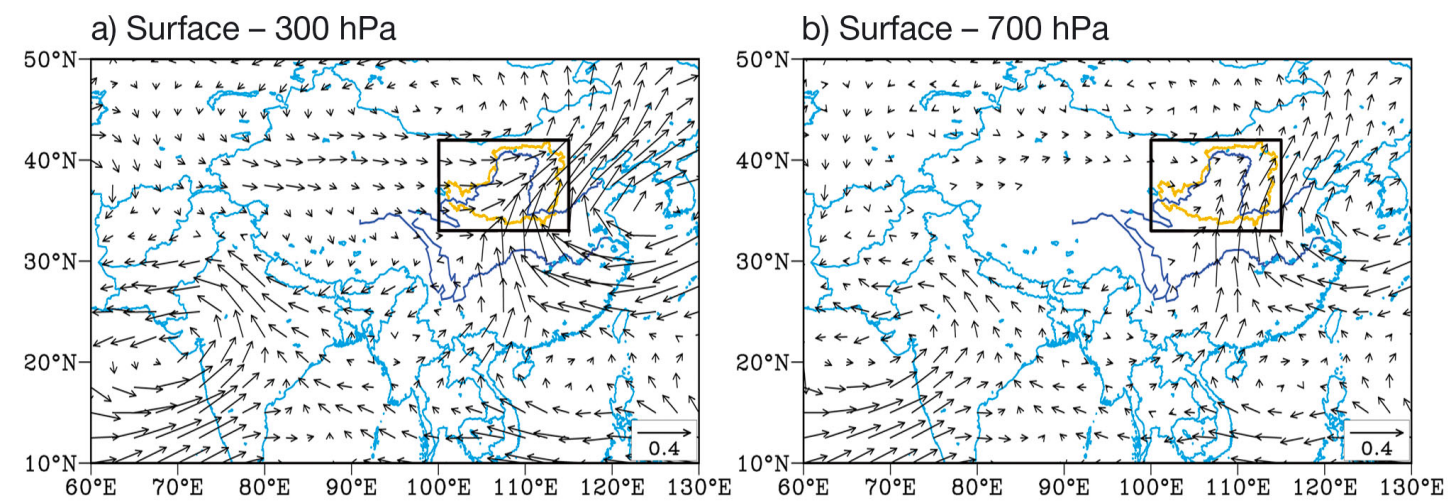

Fig. 9. Regression fields of vertically integrated rainy season (Jun-Sep: JJAS) water vapor transport (in $\mathrm{kg} \mathrm{m}^{-1} \mathrm{~s}^{-1}$ ) at 2 layers of the atmospheric column: (a) surface $300 \mathrm{hPa}$ and (b) surface $700 \mathrm{hPa}$ on the JJAS precipitation index over the Loess Plateau. Black box: see Fig. 5 
a) Wet

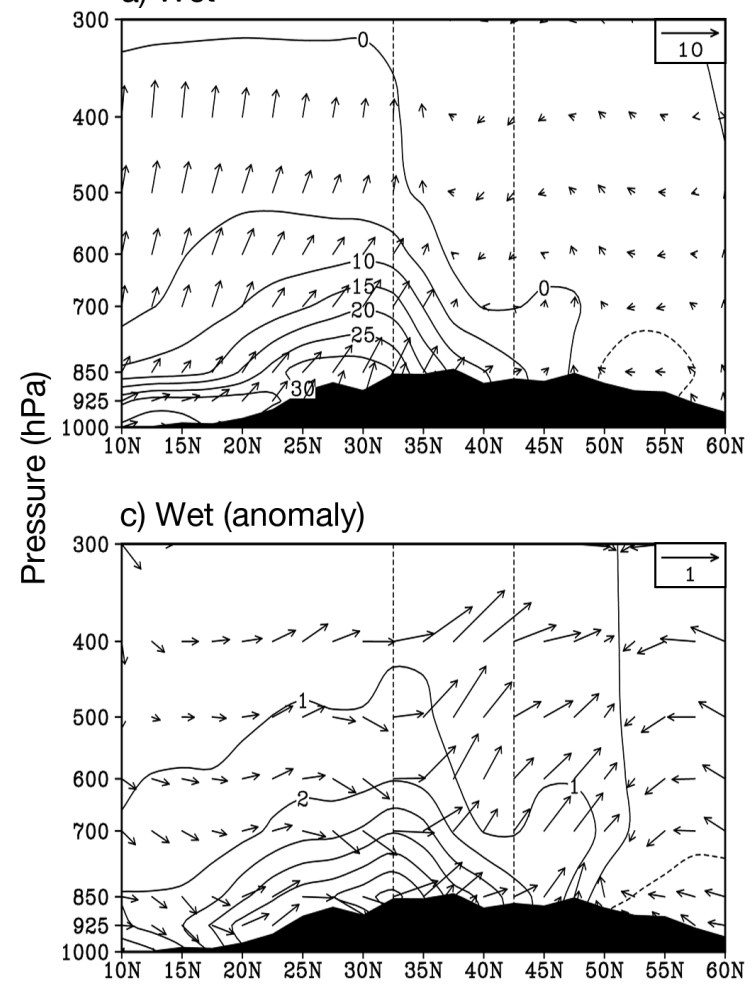

b) Dry

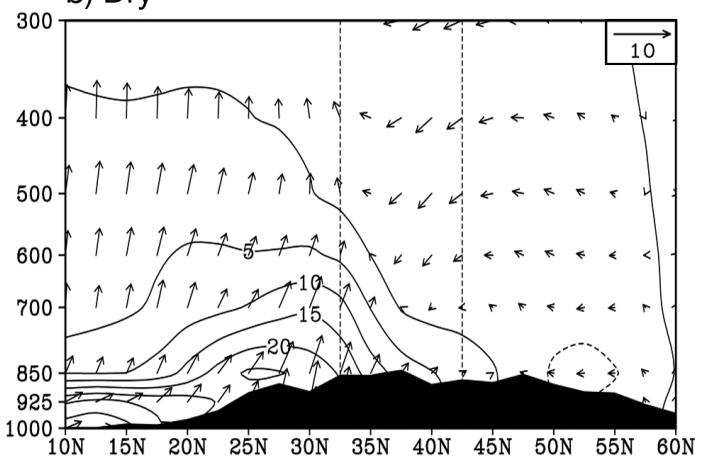

d) Dry (anomaly)

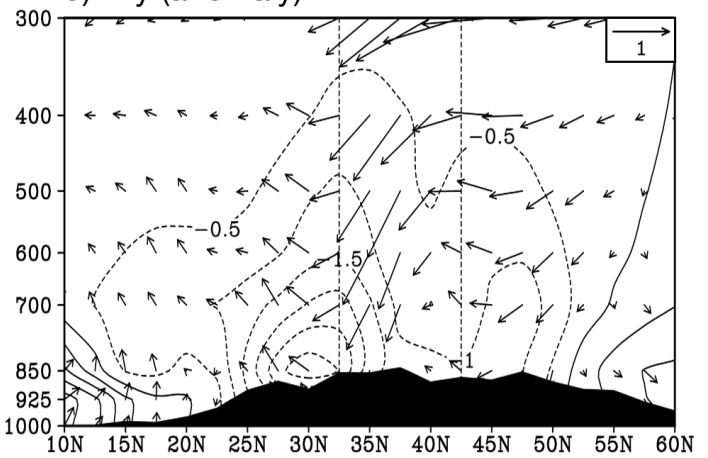

Fig. 10. Latitude-pressure (hPa) cross section of meridional water vapor transport (contours, in $\mathrm{kg} \mathrm{m}^{-1} \mathrm{~s}^{-1}$ ) and wind fields (vectors) composed of meridional wind $\left(\mathrm{m} \mathrm{s}^{-1}\right)$ and vertical velocity $\left(\mathrm{Pa} \mathrm{s}^{-1}\right)$ (enlarged $\left.\times 100\right)$ averaged between the western $\left(100^{\circ} \mathrm{E}\right)$ and eastern $\left(115^{\circ} \mathrm{E}\right)$ boundaries of the Loess Plateau (LP) for (a) wet years, (b) dry years, (c) wet years anomaly, and (d) dry years anomaly. Black area: topography. Vertical dashed lines: southern $\left(32.5^{\circ} \mathrm{N}\right)$ and northern $\left(42.5^{\circ} \mathrm{N}\right)$ boundaries of the LP. Anomalies are calculated based on the difference between the water vapor transport (wind fields) in wet/dry years and the climate mean water vapor transport (wind fields)

the wet years (Fig. 10a) is stronger than in the dry years (Fig. 10b). The northern boundary of summer monsoon moisture shifts northward $\sim 2^{\circ}$ in latitude in the wet years compared with that in the dry years. The wind anomaly fields show that in the wet years (Fig. 10c) the general circulation facilitates the northward transport of water vapor, leading to positive anomaly fields of water vapor transport, but the reverse is observed in the dry years (Fig. 10d).

\section{DISCUSSION AND CONCLUSIONS}

In this paper, we aimed to investigate the variation in the rainy season (JJAS) precipitation over the LP, which is sensitive to changes in the summer monsoon, by using precipitation data from 53 in situ stations, and to quantitatively measure the climate mean water vapor transport and its anomaly in wet/dry years by using NCEP/NCAR reanalysis data set. The main findings are concluded below.
(1) Precipitation data set from 53 in situ stations indicates that the precipitation over the LP peaks in JJAS and exhibits a northwest-southeast increasing gradient. The southeastern LP is more sensitive to the summer monsoon because of larger precipitation SD. The JJAS precipitation of 53 in situ stations for the period 1961-2012 does not show significant increasing or decreasing trends, but the whole LP synchronously becomes wetter or drier. The slope (linear trend) for the JJAS precipitation index of the LP averaged from the 53 stations is $-6.81 \mathrm{~mm}$ decade $^{-1}$, but is not statistically significant at the 0.05 level.

(2) The climatological JJAS water vapor transport analysis shows that 2 main water vapor channels are of importance to rainy season rainfall over the LP. The former is dominated by the Indian and the East Asian monsoons, and the latter is controlled by the Westerlies. The summer monsoon imports moisture mainly through the bottom layer (1000 to $700 \mathrm{hPa}$ ), while the Westerlies carry moisture primarily through the middle layer (700 to $400 \mathrm{hPa}$ ). The water vapor transport from the western boundary is $\sim 73 \%$ of that 
from the southern boundary, indicating a dominating role of the Asian monsoon and the non-negligible role of the Westerlies in providing moisture for rainfall over the LP.

(3) Composite analysis shows that the increased (decreased) water vapor import from both the southern and western boundaries, especially the bottom and middle layer of southern boundaries, facilitates more (less) precipitation over the LP in wet (dry) years. A positive rainfall anomaly of $100 \mathrm{~mm}$ is associated with a positive water vapor import of 166 (23) $\mathrm{kg} \mathrm{m}^{-1} \mathrm{~s}^{-1}$ from the southern (western) boundary. The moisture transport anomalies in wet years and the regression fields both feature a cyclone anomaly centered at the northeastern Indian Ocean, an anticyclone anomaly centered at the Pohai region, and a slight increase in moisture transport by the Westerlies, implying that the strengthened Indian and East Asian monsoons and the slightly increased Westerlies are crucial for excessive precipitation over the LP.

Given the important impact of increased moisture from the southern boundary on excessive precipitation over the LP, we surmise that both the Indian summer monsoon and East Asian monsoon exert important impacts on precipitation over the LP. However, it is still hard to quantitatively measure their individual contribution because they emerge together before reaching the LP. Besides, parallel to the East Asian summer monsoon decline since the end of 1970s (Yu et al. 2004, Xu et al. 2006, Yu \& Zhou 2007, Zhou et al. 2009, $\mathrm{Li}$ et al. 2010a), precipitation over the LP also exhibited a stronger decreasing trend from 1977 to 2000, implying a stronger response to the weakening East Asian summer monsoon during those years (Fig. 4a), which is reported as an East Asia summer monsoon weakening period ( $\mathrm{Li}$ et al. 2010a). However, rainfall is a complex process, and moisture transport by summer monsoon and the Westerlies is only one of the factors affecting the process. How much of the incoming moisture can be transformed into precipitation and surface-available water needs to be addressed in future studies. Lastly, it is worth noting that the water vapor transport derived from NCEP/NCAR over East Asia is stronger than that derived from other datasets (Zhou \& Yu 2005). In order to reduce the uncertainty of the present results, a comparison of water vapor transport between NCEP/NCAR and ERA-interim was performed. The results show that the main incoming and outgoing channels of water vapor are the same in the 2 datasets, although the NCEP/NCAR reanalysis measures a stronger (weaker) water vapor transport by the summer monsoon (the Westerlies) than the ERA-interim data.
Acknowledgements. This work was jointly supported by the Key Research Program of the Chinese Academy of Sciences (Grant KZZD-EW-04-01), the Strategic Priority Research Program of the Chinese Academy of Sciences (XDB03020601), the National Science Foundation of China (41290255) and the West Light Foundation of the Chinese Academy of Sciences. ERA-interim data used in this study have been provided by ECMWF.

\section{LITERATURE CITED}

Ding YH, Ren GY, Shi GY, Gong P and others (2006) National assessment report of climate change. I. Climate change in China and its future trend. Adv Clim Chang Res 2:3-8 (in Chinese)

Fan X, Wang Q, Wang M (2012) Changes in temperature and precipitation extremes during 1959-2008 in Shanxi, China. Theor Appl Climatol 109:283-303

Feng L, Zhou T (2012) Water vapor transport for summer precipitation over the Tibetan Plateau: multidata set analysis. J Geophys Res 117:D20114, doi:10.1029/2011JD0

He JH, Liu YY, Chang Y (2005) Analysis of summer precipitation anomaly and the feature of water vapor transport and circulation in Northwest China. Arid Meteorol 23: 10-16 (in Chinese)

Jin LY, Fu JL, Chen FH (2006) Spatial and temporal distribution of water vapor and its relationship with precipitation over northwest China. J Lanzhou Univ 42:1-6

Kalnay E, Kanamitsu M, Kistler R, Collins W and others (1996) The NCEP/NCAR 40-year reanalysis project. Bull Am Meteorol Soc 77:437-471

Li DL, Wei L, Cai Y, Zhang CJ and others (2003) The present facts and the future tendency of the climate change in northwest China. J Glaciol Geocryol 25:135-142 (in Chinese)

Li H, Dai A, Zhou T, Lu J (2010a) Responses of East Asian summer monsoon to historical SST and atmospheric forcing during 1950-2000. Clim Dyn 34:501-514

Li Z, Zheng FL, Liu WZ, Flanagan DC (2010b) Spatial distribution and temporal trends of extreme temperature and precipitation events on the Loess Plateau of China during 1961-2007. Quat Int 226:92-100

Li Z, Zheng FL, Liu WZ (2012) Spatiotemporal characteristics of reference evapotranspiration during 1961-2009 and its projected changes during 2011-2099 on the Loess Plateau of China. Agric For Meteorol 154:147-155

$>$ Liu BH, Xu M, Henderson M, Qi Y (2005) Observed trends of precipitation amount, frequency, and intensity in China, 1960-2000. J Geophys Res 110:D08103, doi: 10.1029/ 2004JD004864

Ren G, Guo J, Xu M, Chu Z and others (2005) Climate changes of China's mainland over the past half century. Acta Meteorol Sin 63:942-956

> Shi H, Shao MG (2000) Soil and water loss from the Loess Plateau in China. J Arid Environ 45:9-20

Trenberth KE, Guillemot CJ (1995) Evaluation of the global atmospheric moisture budget as seen from analyses. J Clim 8:2255-2272

> Wang YQ, Zhou L (2005) Observed trends in extreme precipitation events in China during 1961-2001 and the associated changes in large-scale circulation. Geophys Res Lett 32:L09707, doi: 10.1029/2005GL022574

Wei N, Gong YF, Sun X, Fang JG (2010) Variation of precipitation and water vapor transport over Northwest China 
from 1959 to 2005. J Desert Res 30:1450-1457 (in Chinese)

Xu M, Chang CP, Fu CB, Qi Y, Robock A, Robinson D, Zhang HM (2006) Steady decline of East Asian monsoon winds, 1969-2000: evidence from direct ground measurements of wind speed. J Geophys Res 111:D24111, doi: 10.1029/2006JD007337

Xu XD, Lu CG, Shi XH, Gao ST (2008) World water tower: an atmospheric perspective. Geophys Res Lett 35: L20815, doi:10.1029/2008GL035867

Yatagai A, Yasunari T (1995) Interannual variations of summer precipitation in the arid/semiarid regions in China and Mongolia: their regionality and relation to the Asian summer monsoon. J Meteorol Soc Jpn 73:909-923

Yu R, Zhou T (2007) Seasonality and three-dimensional structure of interdecadal change in the East Asian monsoon. J Clim 20:5344-5355

Editorial responsibility: Bryson Bates, Wembley, Australia
Yu R, Wang B, Zhou T (2004) Tropospheric cooling and summer monsoon weakening trend over east asia. Geophys Res Lett 31:L22212, doi: 10.1029/2004GL021270

Zhang RH (2001) Relations of water vapor transport from Indian monsoon with that over East Asia and the summer rainfall in China. Adv Atmos Sci 18:1005-1017

Zhou TJ (2003) Comparison of the global air-sea freshwater exchange evaluated from independent datasets. Prog Nat Sci 13:626-631

> Zhou TJ, Yu RC (2005) Atmospheric water vapor transport associated with typical anomalous summer rainfall patterns in China. J Geophys Res 110:D08104, doi: 10.1029/ 2004JD005413

- Zhou T, Gong D, Li J, Li B (2009) Detecting and understanding the multi-decadal variability of the East Asian summer monsoon - recent progress and state of affairs. Meteorol Z 18:455-467

Submitted: January 31, 2013; Accepted: August 9, 2013 Proofs received from author(s): November 4, 2013 